\title{
Um olhar sobre a trajetória histórica e as características da Educação de Jovens e Adultos no Brasil
}

\author{
Maria Consuelo Alves Lima ${ }^{1}$ \\ Rayane de Jesus Santos Melo ${ }^{2}$
}

\begin{abstract}
RESUMO
Este estudo evidencia pontos da trajetória histórica da Educação de Jovens e Adultos (EJA) no Brasil que merecem destaques pelas contribuições favoráveis ou contrárias ao seu desenvolvimento no País. Delineando caminhos percorridos pela EJA, a partir de consultas em referenciais teóricos e documentos oficiais, discutiram-se avanços e retrocessos na cultura jurídica, lutas de movimentos sociais e criação e execução de programas que tiveram o objetivo de erradicar o analfabetismo, tido como "vergonha nacional". Pela visão histórica da EJA, é possível compreender o papel de particularidades de percurso que impulsionaram a promoção e as melhorias no ensino de jovens e adultos na atualidade.
\end{abstract}

PALAVRAS-CHAVE: EJA. História da Educação. Movimentos Sociais.

A look at the historical trajectory of the education young and adults characteristic in Brazil

\begin{abstract}
This study evince the historic point of the trajectory of Adult and Young Education (EJA) of Brazil that deserve to be distinction for the favorable contributions or opposed in your development at country. Introducing the direction go through for the EJA from the research in theoretical reference and official documents discussions were held about advances and setbacks in legal culture, struggles of social movements and the creation and
\end{abstract}

\footnotetext{
${ }^{1}$ Doutora em Física. Universidade Federal do Maranhão, São Luís, Maranhão, Brasil. E-mail: mconsuelo@ufma.br.

${ }^{2}$ Mestra em Ensino de Ciências e Matemática. Universidade Federal do Maranhão, São Luís, Maranhão, Brasil. Email: rayanemelo.27@gmail.com.
} 
execution of programs that had the objective of eradicating illiteracy, considered as "national shame". From the historical understand EJA is possible realize the particularity paper or trajectory that give a boost to the promotion and the improvement of the teaching of adult and young nowadays.

KEYWORDS: EJA. Education History. Social movements.

$$
* * *
$$

\section{Introdução}

A Educação de Jovens e Adultos (EJA) no Brasil ainda é um tema pouco explorado nas pesquisas acadêmicas. Ao estudar os traços históricos, sociais e pedagógicos da EJA, é possível compreender sua origem histórica, características e particularidades, para evitar a concepção mais comum, que é o entendimento dessa educação como simplesmente compensatória e de suplência. Realizar reflexões sobre o atendimento ao sujeito que busca essa modalidade de educação é pensar em mudanças na forma de olhar para a EJA, na perspectiva de conquistar inovações no ensino para esse público.

Buscamos, neste estudo, mostrar pontos da trajetória histórica da Educação de Jovens e Adultos no Brasil: alicerçados principalmente nos estudos realizados por Boff (2002), Friedrich et al. (2010), Haddad e Di Pierro (2000), Paiva (1973), Saviani (2013), Soares e Galvão (2009) e em documentos oficiais, como a Constituição Política do Império do Brasil de 1824, a Lei de Diretrizes e Bases da Educação Nacional no 9394/1996 e o Parecer nº 11/2000, que trata das Diretrizes Curriculares Nacionais para a EJA, abordaremos os principais períodos que constituem a história desse ensino no País.

Iniciaremos as discussões no Período Colonial, com as ações dos jesuítas, consideradas por estudiosos como ponto inicial do movimento de alfabetização nas terras brasileiras. Ao longo do texto, explicitaremos aspectos que merecem destaque, por sua contribuição favorável ou contrária ao desenvolvimento da EJA. 
Este nosso olhar para a história da EJA no Brasil evidencia a necessidade de pensar a educação como direito de todos, uma vez que, desde o início do desenvolvimento das ações educativas no País, a educação ficou restrita a uma pequena parcela da população. A partir da visão histórica da EJA, pode-se compreender o papel de particularidades do percurso que impulsionaram a promoção e as melhorias no ensino de jovens e adultos na atualidade.

\section{Dos primórdios da Educação de Adultos à década de 1950}

Os primeiros movimentos de alfabetização no Brasil iniciaram-se com as ações da Corte portuguesa, interessada em converter os 'gentios' à Santa Fé católica, por intermédio da catequese e do ensino da leitura e da escrita portuguesa. Saviani (2013) relata que o Rei Dom João II enviou Tomé de Sousa para as terras brasileiras, em 1549, como primeiro governador do Brasil, e com ele vieram os primeiros padres jesuítas, chefiados por Manuel da Nóbrega, membro da Companhia de Jesus e designado pelo provincial dos jesuítas de Portugal para comandar a ação de catequização no Brasil. Desde então, e durante todo o período colonial, os religiosos exerceram ações educativas missionárias, em grande parte, com os adultos. Segundo Haddad e Di Pierro (2000, p. 109), "além de difundir o evangelho, tais educadores transmitiam normas de comportamentos e ensinavam os ofícios necessários ao funcionamento da economia colonial, inicialmente aos indígenas, e, posteriormente, aos escravos negros". Fatos que dão indícios de ter sido nesse período da História do Brasil que iniciaram as ações primordiais da Educação de Adultos.

Com a expulsão dos jesuítas, em 1759, e, consequentemente, a desorganização do sistema de ensino, somente no Período Imperial foram encontradas novas informações sobre ações educativas no campo da educação de adultos. O grande destaque do período foi a promulgação da Primeira Constituição Brasileira, em 1824, que prevê "instrução primária gratuita a todos os cidadãos" (BRASIL, 1824), configurando-se como a primeira 
conquista da Educação de Adultos na cultura jurídica brasileira, ação resultante de forte influência europeia, uma vez que o Brasil, na época, se situava como um dos países com o maior índice de pessoas analfabetas.

No entanto, também ficou estabelecido na Constituição que a instrução primária ficaria restrita aos livres e libertos, pois acreditava-se que:

Para escravos indígenas e caboclos - assim se pensava e se praticava - além do trabalho duro, bastaria a doutrina aprendida na oralidade e a obediência na violência física ou simbólica. $\mathrm{O}$ acesso à leitura e à escrita eram tidos como desnecessários e inúteis para tais segmentos sociais. (BRASIL, 2000, p. 13)

Desde então, observa-se o processo de exclusão dos cidadãos da sociedade e a negação do direito de "todos" ao acesso à educação. Esse processo foi reforçado pelo Decreto ${ }^{0}$ 3.029, de 09 de janeiro de 1881, conhecido como 'Lei Saraiva', em homenagem ao Ministro do Império, José Antônio Saraiva, responsável pela primeira reforma eleitoral do Brasil, que instituiu o título de eleitor. Segundo Friedrich et al. (2010, p. 394), "esta lei proibia o voto dos analfabetos por considerar a educação como ascensão social", e também porque, nesse período, o analfabetismo estava associado à incapacidade e à inabilidade social.

Apesar da conquista legal, o período do Império terminou com pouco ou quase nenhum feito para intensificar o processo de alfabetização e minimizar o quadro de analfabetismo do Brasil. Porém, como afirmam Haddad e Di Pierro (2000, p.109), o estabelecimento da instrução primária para todos na Constituição de 1824 "tornou-se semente e enraizou-se definitivamente na cultura jurídica, manifestando-se nas Constituições Brasileiras posteriores".

Segundo Friedrich et al. (2010), na transição do Período Imperial para o Republicano, a educação era considerada como redentora dos problemas da nação brasileira. No entanto, a primeira Constituição Republicana, proclamada em 1891, retirou a referência à gratuidade de instrução, estabelecida na Constituição Imperial, e condicionou o exercício do voto aos 
alfabetizados. $\mathrm{Na}$ época, "esse condicionamento era explicado como uma forma de mobilizar os analfabetos a buscarem, por sua vontade, os cursos de primeiras letras" (BRASIL, 2000, p. 14).

A partir de 1920, vários movimentos civis se empenharam na luta contra o analfabetismo, considerado um "mal nacional", uma "chaga social". Isso ocorreu devido "[a]os surtos de urbanização, [a]os primórdios da indústria nacional e [à][...] necessidade de formação mínima de mão de obra do próprio país" (BRASIL, 2000, p. 15), que motivaram grandes reformas educacionais em quase todos os estados. Esses movimentos ganharam forças, principalmente, com a promulgação da Constituição de 1934, que reconheceu, pela primeira vez em caráter nacional, a educação como direito de todos.

Durante a Era Vargas (1930-1945), como afirmam Friedrich et al. (2010, p. 396), "a educação de adultos foi entendida como peça fundamental na elevação dos níveis de escolarização da população em seu conjunto, compreendendo este processo como fundamental para a elevação do nível cultural dos cidadãos", e, desse modo, foram institucionalizadas escolas, em vários locais do País, com um currículo básico. Esses pesquisadores destacam ainda que essa ação do governo restrita à alfabetização, na época denominada "Fábrica de Leitores", deixou a certeza de que somente a alfabetização não resolveria os problemas sociais: era necessário o desenvolvimento de ações mais amplas com as comunidades, para promover grandes transformações sociais e possibilitar avanços significativos no campo da educação de adultos.

$\mathrm{Na}$ década de 40, foi criado, pelo Decreto-Lei 4.048 de 22 de janeiro de 1942, o Serviço Nacional de Aprendizagem Industrial (SENAI), para corroborar a intenção da sociedade capitalista e dos grupos econômicos dominantes, de preparar mão de obra "qualificada" para atender às demandas da indústria e, assim, gerar riquezas para o País. Para essa parcela da sociedade, "sem educação profissional não haveria desenvolvimento industrial no país" (FRIEDRICH, 2010, p. 395), e foi nesse momento que a educação de adultos se vinculou à educação profissional. 
Segundo Duques (2015), com o final da Segunda Guerra Mundial, a Educação de Adultos foi alvo de esforços internacionais, em defesa da promoção, do fortalecimento e da expansão de programas voltados para esse campo da educação. Nesse período, foram promovidos encontros, seminários e campanhas a favor da ampliação do trabalho educativo, mediante o processo de alfabetização e capacitação profissional de jovens e adultos em distorção de idade ou série. Como parte desse movimento, foi lançada no Brasil, em 1947, a Campanha de Educação de Adolescentes e Adultos (CEAA), concebida como a primeira campanha oficial de caráter nacional para o "combate" ao analfabetismo.

Tendo por objetivo levar a "educação de base" a todos os brasileiros iletrados, nas áreas urbanas e rurais, em pouco tempo, de acordo Soek (2010), a CEAA criou diversas escolas supletivas, movimentando esforços das esferas administrativas, de profissionais e de voluntários. E nesse período começaram a ser produzidos os primeiros materiais didáticos voltados às especificidades do ensino, da leitura e da escrita para os adultos.

Nessa época, como em todos os períodos da história brasileira da Educação de Adultos, a campanha teve altos e baixos, e começou a perder forças com a mudança no governo e a escassez de verbas, o que colocou as ações da campanha na dependência do voluntariado da base popular. Entretanto, como ressaltam Haddad e Di Pierro (2000), a influência da CEAA foi significativa, sobretudo por criar uma infraestrutura voltada ao atendimento a jovens e adultos nos estados e municípios.

\section{Alfabetização e conscientização: de 1950 ao início da década de 1960}

O alto índice de analfabetismo do final da década de 1940 até o início da década de 1950, que, segundo Haddad e Di Pierro (2000), atingia mais da metade da população (56\%) com 15 anos ou mais, provocou a criação de diversas campanhas de curta duração, objetivando erradicar a "vergonha" nacional, termo proferido por muitos intelectuais da época. Porém, com a instauração de cursos aligeirados que visavam apenas formar "máquinas de 
leitores", surgiram várias críticas que, de acordo com Duques (2015, p. 47), pautavam-se em carências administrativas, financeiras e educativas, dadas as fragilidades das orientações pedagógicas. Segundo a autora, houve "denúncias relacionadas à superficialidade do aprendizado, à inadequação do método para os sujeitos adultos, bem como levantes e críticas correlatas ao uso das mesmas cartilhas para as distintas regiões do Brasil".

As críticas e as preocupações manifestadas pelos educadores para redefinir as características específicas e um espaço próprio para atender os sujeitos analfabetos - considerados imaturos e ignorantes -, que eram alfabetizados com as mesmas metodologias utilizadas na educação infantil, contribuíram para uma nova visão do problema do analfabetismo e para a consolidação de um novo paradigma pedagógico para esse campo educacional, cuja referência principal foi o educador pernambucano Paulo Freire. Suas ideias foram expostas, inicialmente, no Seminário Regional Preparatório para o II Congresso Nacional de Educação de Adultos realizado no Rio de Janeiro em 1958. Paiva (1973, p. 210, gripos do autor) afirma que durante as discussões no evento Paulo Freire e outros educadores pernambucanos sugeriram:

[...] revisão dos transplantes que agiram sobre o nosso sistema educativo, a organização de cursos que correspondessem à realidade existencial dos alunos, o desenvolvimento de um trabalho educativo "com" o homem e não "para" o homem, a criação de grupos de estudo e de ação dentro do espírito de autogoverno, o desenvolvimento de uma mentalidade nova no educador, que deveria passar a sentir-se participante no trabalho de soerguimento do país; propunham [...] a renovação dos métodos e processos educativos, substituindo o discurso pela discussão e utilizando as modernas técnicas de educação de grupos com a ajuda de recursos audiovisuais.

As proposições de Paulo Freire baseavam-se em um novo entendimento da relação entre as questões educacionais e sociais que, segundo Paiva (1973, 
p. 216), antes eram apontadas como causa da pobreza e da marginalização. E, durante as ações de Freire no combate ao quadro de exclusão educacional, "o analfabetismo passou a ser interpretado como efeito da situação de pobreza gerada por uma estrutura social não igualitária”.

Mediante a concepção e o pensamento pedagógico estabelecidos por Paulo Freire para a Educação de Adultos, surgiram diversas campanhas, programas de alfabetização e de educação popular, no período de 1959 a 1964, na busca por melhorias para esse campo da educação. Dentre os principais, citamos o Movimento de Educação de Base, criado em 1961 com apoio do governo federal; o Movimento de Cultura Popular do Recife, estabelecido a partir de 1961; os Centros Populares de Cultura, estruturados como sociedades civis em Recife pela administração do Prefeito Miguel Arraes; e a Campanha "De Pé no Chão Também se Aprende a Ler", da Secretaria Municipal de Natal.

Paulo Freire opôs-se ao modelo de "educação bancária", denominada assim por considerar o educando um recipiente vazio que precisava ser preenchido com conhecimento transmitido pelo educador, e elaborou uma proposta de alfabetização de adultos conscientizadora, conhecida como "Método de Paulo Freire" (FREIRE, 1979, 2016), por possuir um conjunto de procedimentos metodológicos com princípios básicos que podem ser traduzidos numa frase sua que se tornou célebre: "A leitura do mundo precede a leitura da palavra”, pois almejava uma educação problematizadora, dialogal e que não negasse a cultura dos educandos (BRASIL, 2000).

Orientados por princípios freirianos, diversos materiais pedagógicos para a alfabetização de adultos foram produzidos na época, com elaboração regional e local, buscando expressar o universo vivencial dos alfabetizandos. Segundo Duques (2015), esses materiais se caracterizavam, sobretudo, por problematizar a realidade imediata dos alfabetizandos e não apenas por trazê-la em relevo. 
No ano de 1961, foi promulgada a Primeira Lei de Diretrizes e Bases da Educação Nacional (LDBEN), Lei $n^{0} 4.024 / 61$, que reconheceu a educação como direito de todos e, no Art. 27 do Título VI, Capítulo II, estabeleceu que:

O ensino primário é obrigatório a partir dos sete anos de idade e só será ministrado na língua nacional. Para os que iniciarem depois dessa idade poderão ser formadas classes especiais ou cursos supletivos correspondentes ao seu nível de desenvolvimento (BRASIL, 1961, p. 8).

A última conquista da educação de adultos, nesse período, aconteceu em janeiro de 1964, com a aprovação do Plano Nacional de Alfabetização, que previa a disseminação, por todo Brasil, de programas orientados pela proposta de Paulo Freire. A preparação do plano, com forte engajamento de estudantes, sindicatos e diversos grupos estimulados pela efervescência política da época, foi interrompida meses depois pelo golpe militar (DUQUES, 2015).

Acredita-se que, se os movimentos de educação de adultos inspirados no pensamento pedagógico de Paulo Freire e daqueles que contaram com o seu apoio tivessem continuado, talvez o índice de analfabetismo tivesse sido amplamente reduzido ou extinto, e muitas outras conquistas teriam sido alcançadas no campo da Educação, uma vez que as propostas de Freire vão além da alfabetização de adultos.

\section{A Alfabetização de Adultos durante o Regime Militar}

Com o golpe militar de 1964, os programas de alfabetização e educação popular, que haviam se multiplicado naquele período, foram reprimidos e tiveram seus dirigentes perseguidos, vistos como uma grave ameaça à ordem. Boff (2002) destaca que líderes como Paulo Freire foram presos e exilados, e muitos professores universitários que estavam engajados no Movimento de Educação e Cultura tiveram seus direitos cassados e suas funções tolhidas. 
Contudo, ao perceberem que não podiam se ausentar deste campo educacional, os militares implantaram programas de alfabetização com caráter conservador, como a Cruzada de Ação Básica Cristã (ABC), programa surgido em Recife e dirigido por evangélicos norte-americanos interessados em ocupar os espaços deixados pelos movimentos populares. O ABC serviu de maneira assistencialista aos interesses do regime militar, ganhando dimensão nacional, mas esse e outros programas foram progressivamente extintos até 1968, após a instauração do Movimento Brasileiro de Alfabetização (Mobral), em 1967, que surgiu para enraizar a ideologia do regime militar.

Criado pela Lei $\mathrm{n}^{\circ} 5.379$ em 15 de dezembro de 1967, apresentou como principais objetivos a erradicação do analfabetismo e a educação continuada de adolescentes e adultos, sendo considerado na época, em sua dimensão social, um instrumento que permitiria a promoção social dos alunos, oferecendo, além do Programa de Alfabetização, o de Educação Integrada, que equivalia ao antigo primário, porém, em formato compacto (MOBRAL, 1973).

Ao iniciar suas atividades, o Mobral estabeleceu prioridades baseadas nas ações de atendimentos, especialmente, (1) à população urbana analfabeta, pois alegava que esse público poderia ser recrutado com maior facilidade e era o que padecia de carências educacionais, uma vez que a vida moderna apresentava grande complexidade e cenário cada vez mais competitivo; (2) à faixa etária de 15 a 35 anos, prioritariamente, uma vez que esse público apresentava "maior probabilidade de desenvolver, em termos de acréscimo de produtividade, os recursos investidos na sua formação, além de considerar mais fácil o ajustamento social por oferecer menor resistência a mudança de vida"; e (3) ao Programa de Alfabetização, preferencialmente ao de Educação Integrada, por duas razões: o Programa de Alfabetização atendia a um maior número de pessoas e era considerado mais democrático, pelo fato de serem os analfabetos, na época, o contingente populacional de menor renda (BRASIL, 1974). 
Para Haddad e Di Pierro (2000), o Mobral se configurou como um programa que atendia aos objetivos de alfabetizar os cidadãos marginalizados do sistema escolar, mas, por outro lado, acolhia os objetivos públicos dos governos militares, que o instituíram como organização autônoma em relação ao Ministério da Educação, contando com um volume significativo de recursos.

Em 1969, o Mobral lançou uma campanha massiva de alfabetização que, segundo Soares e Galvão (2009), conclamou a população a participar, tendo como lema "você também é responsável, então me ensine a escrever, eu tenho a minha mão domável, eu sinto sede de estudar", e recrutou alfabetizadores, sem muita exigência, o que denotou despreocupação com o fazer e o saber docente.

Quatro anos depois da criação do Mobral, foi instituída a LDBEN $n^{\circ}$ 5692/1971, que, em seu capítulo IV, implantou e regulamentou o Ensino Supletivo no País e, segundo Duques (2015), foi estabelecida com o objetivo de reconstruir a escolarização regular, capacitar mão de obra e atualizar conhecimentos, tendo as funções de Suplência, Suprimento, Aprendizagem e Qualificação. Haddad e Di Pierro (2000, p. 117) explicam que

a Suplência tinha como objetivo: suprir a escolarização regular para os adolescentes e adultos que não a tenham seguido ou concluído na idade própria através de cursos e exames [...]. O Suprimento tinha como finalidade proporcionar, mediante repetida volta à escola, estudos de aperfeiçoamento ou atualização para os que tenham seguido o ensino regular no todo ou em parte [...]. A aprendizagem correspondia a formação metódica no trabalho, e ficou a cargo basicamente do SENAI e do SENAC. A Qualificação foi a função encarregada da profissionalização que, sem ocupar-se com a educação geral, atenderia ao objetivo prioritário de formação de recursos humanos para o trabalho. 
Dada sua flexibilidade, o Ensino Supletivo, até o final do período militar, apresentou-se como uma possibilidade para quem não teve a oportunidade de escolarização na idade certa, ao mesmo tempo em que se colocou como um meio de atualização para os que quisessem acompanhar o movimento de modernização da sociedade, conforme pontua Duques (2015).

\section{A Educação de Adultos, do pós-Regime Militar aos dias atuais}

Com o fim do Regime Militar, em 1985, o governo dos civis, buscando redemocratizar as relações sociais e as instituições públicas nacionais, extinguiu o Mobral e em seu lugar implantou a Fundação Educar. Soares e Galvão (2009) revelam que os últimos anos do Mobral foram marcados por denúncias que culminaram na criação de uma Comissão Parlamentar de Inquérito para apurar os destinos e a aplicação dos recursos financeiros e a divulgação de falsos índices de analfabetismo. E, pedagogicamente, o Mobral foi criticado por não garantir a continuidade dos estudos: muitos adultos alfabetizados por ele, posteriormente, "desaprenderam" a ler e escrever.

Diferentemente do Mobral, a Fundação Educar mantinha relações diretas com o Ministério da Educação e não desenvolvia ações de alfabetização. Sua função, segundo Soares e Galvão (2009), era apenas supervisionar e acompanhar as instituições e as secretarias, que recebiam os recursos transferidos para a execução de seus programas.

A busca pela redemocratização, pós-Regime Militar, foi por contradições entre a afirmação, no plano jurídico, do direito formal à educação básica da população jovem e adulta e sua negação pelas políticas públicas concretas (HADDAD; DI PIERRO, 2000). Esse paradoxo pode ser visto a partir da promulgação da Constituição Federal de 1988, que estendeu o direito à educação aos que ainda não haviam frequentado ou concluído o ensino fundamental. Ao mesmo tempo em que foi proclamado esse direito na cultura jurídica, o Presidente Collor de Melo (1990-1992), no seu primeiro ano de mandato, extinguiu a Fundação Educar, o que comprometeu a articulação 
nacional na política de alfabetização no Brasil e provocou desorganizações no campo da educação de adultos.

Sem o apoio do governo federal, órgãos públicos, as entidades civis e outras instituições que inicialmente eram conveniadas à Fundação Educar tiveram que arcar sozinhos com as atividades educativas desenvolvidas com jovens e adultos. Portanto, esse período foi marcado pela transferência direta de responsabilidade pública dos programas de alfabetização e pósalfabetização da União para os municípios. Nos anos seguintes, os municípios tiveram um crescimento contínuo na matrícula do primeiro segmento do ensino fundamental de jovens e adultos, e os estados concentraram-se nas matrículas do segundo segmento do ensino fundamental e do ensino médio (HADDAD; DI PIERRO, 2000).

Passados seis anos da extinção da Fundação Educar, o governo federal voltou a participar de ações para combater as taxas de analfabetismo. Eleito Presidente da República em 1994 e reeleito em 1998, Fernando Henrique Cardoso (1995-2002) buscou priorizar a implementação de uma reforma político-institucional da educação pública que compreendeu diversas medidas, dentre as quais, segundo Haddad e Di Pierro (2000), estavam a aprovação de uma emenda constitucional e a promulgação de uma nova LDBEN.

Aprovada pelo Congresso no fim de 1996, a LDBEN nº 9394 estabelecia que o processo de alfabetização destinado a jovens e adultos que não tiveram a oportunidade de concluir os estudos na idade apropriada passava a ser reconhecido como modalidade de educação, denominado Educação de Jovens e Adultos. Essa Lei reduziu as idades de ingresso dos educandos na EJA: 15 anos para o ensino fundamental e 18 anos para o ensino médio. Embora o documento tenha uma seção destinada a essa modalidade de ensino, Haddad e Di Pierro (2000) afirmam que foram curtas e poucas as inovações que a nova Lei apresentou - dentre elas, a extinção da distinção entre os subsistemas de ensino regular e supletivo, integrando organicamente a EJA ao ensino básico comum. 
Ao final da década de 1990, foi criado o Fundo de Manutenção do Ensino Fundamental e Valorização do Magistério (FUNDEF), que, segundo Duques (2015, p. 52), "redefiniu as formas de gerenciamento das políticas educacionais e estabeleceu retrocessos na educação de jovens e adultos do país". Como forma de superar os tratamentos ineficientes dados à EJA, a LDBEN deu destaque para a Educação Profissional e, posteriormente, alguns artigos foram regulamentados pelo Decreto $\mathrm{n}^{0}$ 2.208/1997, que favoreceu a oferta de cursos de formação de curta duração, como o Programa de Alfabetização Solidária (PAS); o Programa Nacional de Educação na Reforma Agrária (PRONERA); e o Plano Nacional de Formação do Trabalhador (PLANFOR).

No século XXI, diversas reflexões se manifestam, com o objetivo de responder aos desafios da sociedade atual. Para superar as fragilidades e os problemas da EJA, o Presidente Luís Inácio Lula da Silva (2003-2010) anunciou que a alfabetização de jovens e adultos seria prioridade em seu governo e, para concretizar essa ação, lançou, em 2003, o Programa Brasil Alfabetizado. Segundo Soares e Galvão (2009, p. 273):

No início, o programa foi visto como mais uma campanha por suas características serem semelhantes a ações de períodos anteriores. Com ênfase no trabalho voluntariado, o Programa previa erradicar o analfabetismo em 4 anos atuando sobre 20 milhões de brasileiros. Previa-se um mês de preparação do alfabetizador e 5 meses para a ação direta de alfabetização. Em 2004, com a mudança de ministros, o programa é redefinido em alguns pontos: retirou-se a meta de erradicar o analfabetismo em 4 anos e a duração dos projetos de alfabetização foi ampliada de 6 para 8 meses.

Retornando à ideia de unir a Educação de Jovens e Adultos à Educação Profissional da Era Vargas, foi criado, em 2005, o Programa Nacional de Integração da Educação Profissional com a Educação Básica na Modalidade 
de Educação de Jovens e Adultos (PROEJA). Nessa mesma vertente do mundo do trabalho, e no mesmo ano, o governo também criou o Programa Nacional de Inclusão de Jovens (PROJOVEM).

Ao longo da evolução histórica da Educação de Adultos no Brasil muitas ações continuam pautadas em modelos seculares, ainda que algumas mudanças sejam observadas no sentido de resguardar as especificidades da EJA. Como aponta Oliveira (2012, p. 165), "nos últimos anos estão sendo percebidas mudanças no perfil identitário da EJA, sem, contudo, observarmos alterações nas políticas educacionais que beneficiem essa modalidade de ensino". Se essas políticas não propuserem mudanças na formação do licenciado, de modo a atender as necessidades dos jovens e adultos, eles, sistematicamente, serão deixados à margem do sistema educativo.

\section{Considerações finais}

A Educação de Jovens e Adultos, ao longo da história da Educação brasileira, passou por diferentes contextos, apresentando conquistas e retrocessos, e contou com o apoio de educadores e de movimentos sociais. Porém, ela continua à margem da sociedade, não por falta de luta, mas por falta de políticas públicas de sustentação para garantir a todos o direito à Educação.

As diferentes ações desenvolvidas para a educação dos jovens e adultos ao longo do tempo foram marcadas por políticas relutantes em relação às necessidades da educação popular. Na cultura jurídica, constatamos pontos contrários ao desenvolvimento da educação desse público, como a promulgação da Primeira Constituição Brasileira, em 1824, que estabeleceu a instrução primária gratuita apenas aos livres e libertos, condicionando o direito à Educação a uma pequena parcela da população. Avanços mais significativos foram estabelecidos somente com a promulgação da Constituição Federal de 1988, que instituiu a Educação como direito de todos, e da Lei de Diretrizes e Base da Educação Nacional nº 9394/1996, que definiu 
a nomenclatura "Educação de Jovens e Adultos" e a reconheceu como modalidade da Educação Básica.

No campo dos movimentos sociais, a Educação de Jovens e Adultos contou com numerosos projetos que tiveram como objetivos a erradicação do analfabetismo e a garantia do direito à Educação. No entanto, sem o apoio político e financeiro, poucos foram os avanços conquistados pela EJA ao longo do tempo, o que se reflete, nos dias atuais, na visão daqueles para quem essa educação é simplesmente compensatória e de suplência, quando deveriam vêla como uma modalidade voltada para um público específico, que ainda não recebeu das políticas públicas a atenção necessária.

Dadas as peculiaridades da EJA, faz-se necessário investir em políticas públicas voltadas para a formação de professor da EJA como forma de conceder um olhar diferenciado aos jovens, adultos e idosos, possibilitandolhes vivenciar o pleno desenvolvimento da cidadania e uma formação para o mercado de trabalho.

\section{Agradecimentos}

As autoras agradecem a Fundação de Amparo à Pesquisa e ao Desenvolvimento Científico e Tecnológico do Maranhão (FAPEMA) pelo apoio concedido a este trabalho. A primeira autora pela bolsa de mestrado e a segunda autora pelo financiamento ao projeto com processo FAPEMA UNIVERSAL-01449/16.

\section{Referências}

BOFF, L. A. As políticas públicas de Educação de Jovens e Adultos no estado de Mato Grosso 1991/200: internalidade e diálogos com o mundo da vida dos jovens e adultos. 2002. Dissertação (Mestrado em Educação) - Faculdade de Educação, Programa de Pós-Graduação em Educação, Universidade Federal do Rio Grande do Sul, Porto Alegre, 2002.

BRASIL. Constituição Política do Império do Brasil, de 25 de março de 1824. Disponível em: <http://www.planalto.gov.br/ccivil_03/constituicao/constituicao 24.htm>. Acesso em: 10 jun. 2018. 
. Lei $\mathrm{n}^{0}$ 4.024, de 20 de dezembro de 1961. Lei de Diretrizes e Bases da Educação Nacional. Disponível em: <http://www.planalto.gov.br/ccivil_03/Leis/ 14024.htm>. Acesso em: 10 jun. 2018.

. Lei $\mathrm{n}^{\circ} 5.692$, de 11 de agosto de 1971. Diretrizes e Bases para o ensino de $1^{\circ} \mathrm{e}$ $2^{\circ}$ graus, $e$ dá outras providências. Disponível em: <http://www.planalto.gov.br/ccivil_03/Leis/15692.htm>. Acesso em: 10 jun. 2018.

- Movimento Brasileiro de Alfabetização e Assessoria de Organização e Métodos. MOBRAL: sua origem e evolução. 1973. Disponível em: $<$ http://www.dominiopublico.gov.br/download/texto/me002033.pdf $>$. Acesso em: 10 jun. 2018.

- Movimento Brasileiro de Alfabetização e Assessoria de Organização e Métodos. Manual do Alfabetizador. Rio de Janeiro: Primor, 1974. 63 p.

Lei $\mathrm{n}^{\circ}$ 9.394, de 20 de dezembro de 1996. Lei de Diretrizes e Bases da Educação Nacional. Disponível em: <http://www.planalto.gov.br/ccivil_03/leis/ L9394.htm>. Acesso em: 10 jun. 2018

Parecer n ${ }^{0}$ 11/2000. Diretrizes Curriculares Nacionais para a Educação de Jovens e Adultos. Disponível em: <http://portal.mec.gov.br/secad/arquivos/df/eja/ legislacao/parecer_11_2000.pdf>. Acesso em: 10 jun. 2018.

DUQUES, M. L. F. Formação de educadores de jovens e adultos: um olhar reflexivo para o desenvolvimento e o aperfeiçoamento da prática docente no município de Matina-BA. Dissertação (Mestrado em Educação de Jovens e Adultos) Universidade do Estado da Bahia, Salvador, 2015.

FREIRE, P. Conscientização: teoria e prática da libertação: uma introdução ao pensamento de Paulo Freire. São Paulo: Cortez e Moraes, 1979.

. Educação como prática da liberdade. 39. ed. São Paulo: Paz e Terra, 2016.

FRIEDRICH, M. et al. Trajetória de escolarização de jovens e adultos no Brasil: de plataformas de governos a propostas pedagógicas esvaziadas. Ensaio: Avaliação e Políticas Públicas em Educação, Rio de Janeiro, v. 18, n. 67, p. 389-410, abr./jun. 2010.

HADDAD, S.; DI PIERRO, M. C. Escolarização de jovens e adultos. Revista Brasileira de Educação, Campinas/SP, n.14, p.108-130, maio/ago. 2000.

OLIVEIRA, M. O. M. Tornar visível o cotidiano da escola: experiências na EJA. Educação e Contemporaneidade - Revista da FAEEBA, Salvador, v. 21, n. 37, p. 163172, jan./jun. 2012.

PAIVA, V. P. Educação popular e educação de adultos. São Paulo: Loyola, 1973.

SAVIANI, D. História das ideias pedagógicas no Brasil. 4. ed. Campinas: Autores Associados, 2013. 
SOARES, L.; GALVÃO, A. M. O. Uma história da alfabetização de adultos no Brasil. In: STEPHANOU, M.; BASTOS, M. H. C. (Org.). Histórias e memórias da educação no Brasil. 3. ed. Petrópolis: Vozes, 2009.

SOEK, A. M. Fundamentos e metodologia da educação de jovens e adultos. Curitiba: Fael, 2010

Recebido em julho de 2018.

Aprovado em dezembro de 2018. 